Article

\title{
Plasma-Assisted MOCVD Growth of Non-Polar GaN and AlGaN on Si(111) Substrates Utilizing GaN-AlN Buffer Layer
}

\author{
Pepen Arifin ${ }^{1, *} \mathbb{0}$, Heri Sutanto ${ }^{2}\left(\mathbb{D}\right.$, Sugianto $^{3}$ and Agus Subagio ${ }^{2}$ \\ 1 Department of Physics, Physics of Electronic Materials Research Division, Faculty of Mathematics and \\ Natural Sciences, Institute of Technology Bandung, Jl. Ganesha 10, Bandung 40132, Indonesia \\ 2 Department of Physics, University of Diponegoro, Jl. Prof. Soedharto, SH, Tembalang, Semarang 50275, \\ Indonesia; herisutanto@live.undip.ac.id (H.S.); agussubagio@lecturer.undip.ac.id (A.S.) \\ 3 Department of Physics, Universitas Negeri Semarang, Sekaran, Gunungpati, Semarang 50229, Indonesia; \\ sugianto@mail.unnes.ac.id \\ * Correspondence: pepen@fi.itb.ac.id
}

check for

updates

Citation: Arifin, P.; Sutanto, H.;

Sugianto; Subagio, A. PlasmaAssisted MOCVD Growth of Non-Polar GaN and AlGaN on Si(111) Substrates Utilizing GaN-AlN Buffer Layer. Coatings 2022, 12, 94. https://doi.org/10.3390/ coatings12010094

Academic Editors: Massimo Longo and Torsten Brezesinski

Received: 5 December 2021

Accepted: 11 January 2022

Published: 14 January 2022

Publisher's Note: MDPI stays neutral with regard to jurisdictional claims in published maps and institutional affiliations.

Copyright: (C) 2022 by the authors. Licensee MDPI, Basel, Switzerland. This article is an open access article distributed under the terms and conditions of the Creative Commons Attribution (CC BY) license (https:// creativecommons.org/licenses/by/ $4.0 /)$

\begin{abstract}
We report the growth of non-polar GaN and AlGaN films on $\mathrm{Si}(111)$ substrates by plasmaassisted metal-organic chemical vapor deposition (PA-MOCVD). Low-temperature growth of GaN or AlN was used as a buffer layer to overcome the lattice mismatch and thermal expansion coefficient between $\mathrm{GaN}$ and $\mathrm{Si}(111)$ and $\mathrm{GaN}$ 's poor wetting on $\mathrm{Si}(111)$. As grown, the buffer layer is amorphous, and it crystalizes during annealing to the growth temperature and then serves as a template for the growth of GaN or AlGaN. We used scanning electron microscopy (SEM), atomic force microscopy (AFM), and X-ray diffraction (XRD) characterization to investigate the influence of the buffer layer on crystal structure, orientation, and the morphology of GaN. We found that the GaN buffer layer is superior to the AlN buffer layer. The thickness of the GaN buffer layer played a critical role in the crystal quality and plane orientation and in reducing the cracks during the growth of GaN/Si(111) layers. The optimum GaN buffer layer thickness is around $50 \mathrm{~nm}$, and by using the optimized GaN buffer layer, we investigated the growth of $\mathrm{AlGaN}$ with varying $\mathrm{Al}$ compositions. The morphology of the AlGaN films is flat and homogenous, with less than $1 \mathrm{~nm}$ surface roughness, and has preferred orientation in $a$-axis.
\end{abstract}

Keywords: non-polar GaN; AlGaN; PA-MOCVD; buffer layer; Si(111); m-plane GaN; a-plane GaN

\section{Introduction}

The unique properties of GaN and related III-nitrides, such as direct wide-bandgap, high thermal stability, and high voltage breakdown, have attracted interest. These properties make them suitable for use as visible and ultraviolet optoelectronic devices and high-power and high-frequency electronic devices [1-3]. GaN-based devices are usually made on sapphire substrates and grown in a $c$-axis oriented wurtzite epilayer using various techniques such as molecular-beam epitaxy (MBE) and MOCVD. However, using sapphire substrate in GaN-based devices has raised several problems associated with the sapphire substrates. First, sapphire has a low thermal conductivity, making it difficult to transfer heat [4]. As a result, heat generated in GaN-based devices with sapphire as a substrate cannot be dissipated quickly, causing degrading device performance and shortening of a lifetime. Secondly, internal spontaneous and piezoelectric polarization processes in $\mathrm{GaN}$ based heterostructures can generate a significant electric field at the nitrides interface causes increasing the radiative lifetime [5] and lowering quantum efficiency [6].

There are two approaches to resolve the polarization problem. One option is to use cubic $\mathrm{GaN}$, which is non-polar in the cubic [001] direction, thus avoiding polarizationinduced electric fields at heterointerfaces. Unfortunately, cubic GaN is metastable, and producing it is challenging. The alternative option is to use hexagonal $\mathrm{GaN}$ in the $a$ - or $m$-plane rather than the $c$-plane, which is known as non-polar GaN such as (1010) and 
$(11 \overline{2} 0)$ planes $[7,8]$. There is no polarization-induced electric field in nitrides interfaces for this type of orientated $\mathrm{GaN}$; therefore, non-polar $\mathrm{GaN}$ materials are advantageous for attaining high internal quantum efficiency $[9,10]$.

Non-polar GaN has been grown on various substrates with or without interlayer by various techniques. Silicon substrate is attractive because it is inexpensive and available in large sizes, making it excellent for fabricating low-cost GaN-based devices. In particular, $\mathrm{Si}(111)$ is widely used as a substrate for the growth of $c$-axis oriented $\mathrm{GaN}$-based devices due to the excellent match of hexagonal GaN with the threefold surface symmetry of $\mathrm{Si}(111)$. Other silicon substrate types have also been shown to be suitable for the growth of GaN on $\mathrm{Si}$, such as $\mathrm{Si}(001)$ and $\mathrm{Si}(110)[11,12]$. However, to date, only a few studies have used $\mathrm{Si}(111)$ as a substrate for the growth of non-polar GaN.

Compared to sapphire, silicon has some advantages, such as it poses higher thermal conductivity, which is four times greater than sapphire [13]. As a result, GaN-based devices fabricated on $\mathrm{Si}(111)$ substrates will have superior heat dissipation. However, the growth of heteroepitaxial GaN on Si raises several challenges, such as significant mismatches in the lattice parameter and thermal expansion coefficient between $\mathrm{GaN}$ and $\mathrm{Si}$ substrates [14,15]. Another problem is GaN's poor wetting on $\mathrm{Si}(111)$, which prevents direct nucleation that typically leads to poor GaN morphology and crystal quality [16]. These are similar to that encountered in the heteroepitaxial growth of $\mathrm{GaAs}$ on $\mathrm{Si}$. In that case, using an amorphous GaAs buffer layer leads to a better-quality GaAs epilayer [17].

MOCVD is a well-known technique for growing GaN for optoelectronic and electronic devices applications. Thermal MOCVD involves cracking $\mathrm{NH}_{3}$ as a nitrogen source and reacting it with trimethyl/tetraethylgallium (TMGa/TEGa) as a gallium source at a high temperature (in the vicinity of $1100^{\circ} \mathrm{C}$ ). Such high temperatures may create issues, such as atomic diffusion and thermal expansion during the cooling process that leads to difficulty obtaining crack-free GaN layers. Many approaches to reduce cracks and improve crystal quality have been reported, including using a step-graded AlGaN interlayer [18], AlN/GaN superlattice [19], and low-temperature AlN (LT-AlN) interlayer [20]. However, as compared to $\mathrm{GaN}$ grown on a sapphire substrate, these approaches have not produced a perfect crackfree $\mathrm{GaN} / \mathrm{Si}(111)$ epitaxy.

Since using such high temperatures in the MOCVD technique raises some problems, we propose a plasma-assisted MOCVD technique to grow non-polar AlGaN on a $\mathrm{Si}(111)$ substrate in this study. Plasma-assisted MOCVD employs microwave radiation to generate reactive nitrogen plasma that can react with gallium at a significantly low temperature of around $700{ }^{\circ} \mathrm{C}$ [21]. Due to the varied crystallographic orientations, the growth conditions for non-polar GaN materials differ from those for c-plane GaN. Here we study and optimize the effect of GaN and AlN buffer layer thickness on the GaN and AlGaN crystallites orientation and morphology. The buffer layer was grown at low temperatures resulting in amorphous $\mathrm{GaN}$ or AlN, which crystallized during the temperature ramp to the growth temperature and maintained the temperature for $20 \mathrm{~min}$. The crystallized GaN and AlN then serve as a template for GaN and AlGaN growth.

\section{Materials and Methods}

Experimental detail of $\mathrm{GaN}$ and $\mathrm{AlGaN}$ growth is similar to that described in [21]. A high purity (99.999\%) nitrogen gas was used and transported to the reactor (home-built) through a downstream cavity type of $2.45 \mathrm{GHz}$ ECR plasma source (ASTeX) to produce nitrogen plasma. Trimethylgallium (TMGa) was used as a gallium source, while the reactive nitrogen species from nitrogen plasma were used as a nitrogen source. Hydrogen gas was used as carrier gas and was purified by passing it through a heated palladium cell.

The $\mathrm{Si}(111)$ substrates were chemically cleaned using the RCA procedure, and they were immediately loaded into the reactor and heated up to $650{ }^{\circ} \mathrm{C}$ for thermal cleaning in the $\mathrm{H}_{2}$ ambient. In-situ hydrogen plasma cleaning of the substrates was carried out for 10 min using 200 watts plasma power with the $\mathrm{H}_{2}$ flow rate of $50 \mathrm{sccm}$. The temperature 
was then decreased to $500-550{ }^{\circ} \mathrm{C}$ to grow $\mathrm{GaN}$ or AlN buffer layer with TMGa flow rate of $0.12 \mathrm{sccm}$ and $\mathrm{N}_{2}$ flow rate of $90 \mathrm{sccm}$.

The experiment started with investigating the effect of $\mathrm{GaN}$ and $\mathrm{Al}$ buffer layer thickness on the structural and morphology characteristics of GaN. The buffer layer was grown for 5-15 min, resulting in buffer layers with thicknesses of around 16-50 nm. According to our routine growth process, $\mathrm{GaN}$ or AlN layers grown at $500-550{ }^{\circ} \mathrm{C}$ are amorphous. After the buffer layer was deposited, the substrate temperature was slowly ramped to $680^{\circ} \mathrm{C}$. The amorphous buffer layer underwent a crystallization process during the temperature ramp to $680^{\circ} \mathrm{C}$ and was maintained for about $20 \mathrm{~min}$. On top of the buffer layer, $\mathrm{GaN}$ film was grown for $2 \mathrm{~h}$ using TMGa and a nitrogen flow rate of around 0.1 and $90 \mathrm{sccm}$, respectively.

We characterized the structural and morphology properties of the grown GaN and determined the optimized buffer layer thickness. Based on the optimized buffer layer thickness obtained from the growth of $\mathrm{GaN}$, we grew $\mathrm{AlGaN}$ with variations in the flow rate of $\mathrm{TMAl} /(\mathrm{TMAl}+\mathrm{TMGa})$ of $10 \%-40 \%$ with a $\mathrm{V} / \mathrm{III}$ ratio of 650 at a growth temperature of $700{ }^{\circ} \mathrm{C}$. The growth temperature is somewhat higher than that of $\mathrm{GaN}$ film because TMGa has a higher vapor pressure than TMAl at the same temperature. As a result, AlGaN thin films require a higher growth temperature than $\mathrm{GaN}$ thin films. The crystallographic structure of GaN and AlGaN films was investigated by XRD (Philips, PW3710, Almelo, The Netherlands), while SEM (JEOL, JSM-6510LA, Tokyo, Japan) and AFM (Seiko Instruments, SPA-400, Chiba, Japan) were used to examine the surface morphology of the samples. The atomic composition of the films was determined using an energy dispersive X-ray analyzer (EDS), integrated with SEM.

\section{Results}

\subsection{Growth of $G a N$}

GaN films were grown directly on top of a low-temperature growth of GaN or AlN buffer layer. The buffer layer was deposited with different growth times, resulting in different GaN and AlN thicknesses. Table 1 shows the thickness of each buffer layer, which was estimated from cross-sectional SEM measurements of the thicker buffer layer. The other buffer layers thicknesses were deduced from the growth time assuming a constant growth rate. Figure 1 shows the surface morphology of GaN films grown with and without a buffer layer. The morphology of $\mathrm{GaN}$ without a buffer layer (sample A) appears to be dominated by hexagonal islands separated by about $0.2-0.6 \mu \mathrm{m}$. The island separation indicates a non-uniform three-dimensional growth mode, and nucleation dispersion occurs, resulting in a partial covering of the substrate surface. This type of growth mode is most likely due to a lattice mismatch between $\mathrm{GaN}$ and the Si substrate and a significant divergence in interfacial energy between $\mathrm{GaN}$ and $\mathrm{Si}$. Therefore, the growth of $\mathrm{GaN}$ film directly on top of Si results in the nucleation of separate islands. The formation of separated grain islands suggests that the nucleation rate is substantially low.

Table 1. Buffer layer thickness and $\mathrm{Ga} / \mathrm{N}$ atomic ratio of $\mathrm{GaN}$ films grown with different buffer layer thicknesses.

\begin{tabular}{ccccc}
\hline Sample & $\begin{array}{c}\text { Buffer Layer } \\
\text { Thickness (nm) }\end{array}$ & \% At (Ga) & \% At (N) & Ga/N Ratio \\
\hline A & Without buffer & 61.45 & 38.55 & 1.59 \\
\hline B & GaN (16 nm) & 62.04 & 37.96 & 1.63 \\
\hline C & GaN (33 nm) & 57.18 & 42.82 & 1.34 \\
\hline D & GaN (50 nm) & 55.92 & 44.08 & 1.27 \\
\hline E & AlN (29 nm) & 63.89 & 36.11 & 1.77 \\
\hline F & AlN $(44 \mathrm{~nm})$ & 60.97 & 39.03 & 1.56 \\
\hline
\end{tabular}



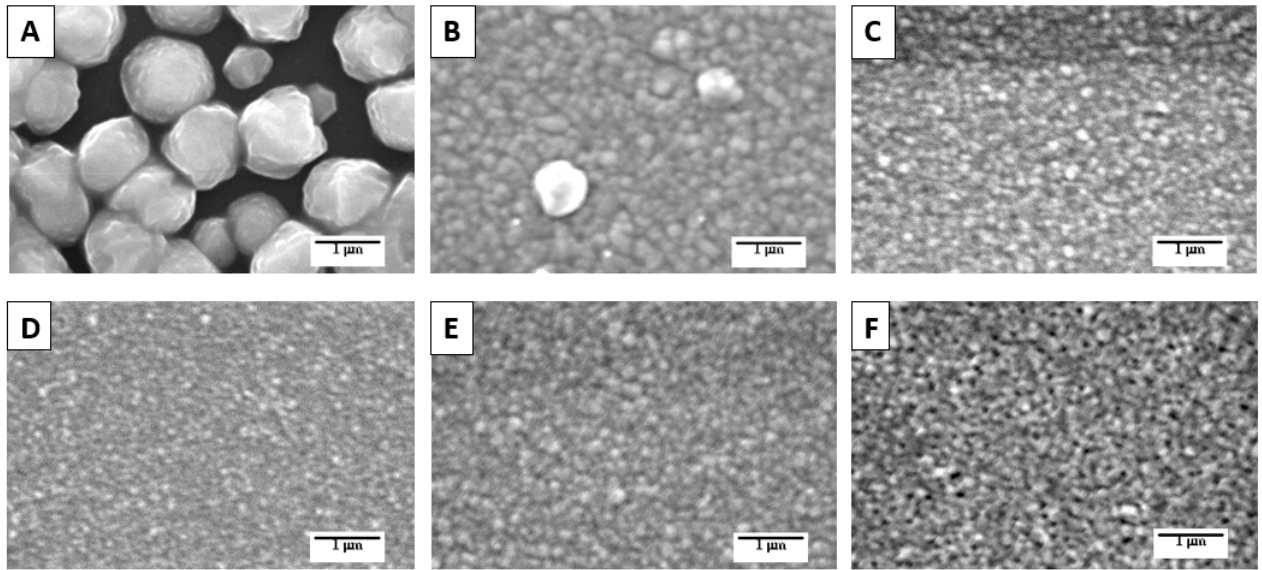

Figure 1. SEM images of the surface morphology of GaN films grown on $\mathrm{Si}(111)$ with different buffer layer thicknesses. (A) (without buffer layer), (B-D) (GaN buffer layer, with thicknesses of 16, 33, and $50 \mathrm{~nm}$, respectively), (E,F) (AlN buffer layer with thicknesses of 29 and $44 \mathrm{~nm}$ ).

In the heteroepitaxy process, the nucleation process plays an important role. Because of the structural and chemical incompatibilities between $\mathrm{GaN}$ and $\mathrm{Si}$, growing $\mathrm{GaN}$ directly on Si substrate is difficult. The nitridation of the Si surface could be one cause for the poor wetting of $\mathrm{GaN}$ deposition on $\mathrm{Si}$. If MOCVD is used with $\mathrm{NH}_{3}$ as a nitrogen source, $\mathrm{Si}$ will easily react with $\mathrm{NH}_{3}$ at temperatures above $500{ }^{\circ} \mathrm{C}$ to form $\mathrm{Si}_{3} \mathrm{~N}_{4}$ [22] during the annealing process. Consequently, nitridation problems can be avoided using an ammoniafree atmosphere during the first growth stage. Therefore, we use plasma nitrogen to cover Si substrate with low-temperature growth amorphous GaN layer to minimize this nitridation process. This technique is expected to increase $\mathrm{GaN}$ wetting on $\mathrm{Si}$ and provide a homogeneous surface for $\mathrm{GaN}$ upper growth.

Figure 1B-F shows the morphology of GaN films deposited with various buffer layers thickness. According to the SEM results, GaN film morphologies depend significantly on the thickness of the buffer layer. As the GaN film was grown with a buffer layer, either GaN or AlN (samples B to F), almost homogeneous grains ( 0.05 $\mu \mathrm{m}$ in size) are formed, demonstrating lateral growth occurs. These findings suggest that the buffer layer effectively reduces the interfacial energy between the substrate and the GaN film, allowing for a faster coalition process between islands, as evidenced by the smaller grain size formed.

SEM images of samples B to D show that the grain size becomes smaller as the thickness of the buffer layer increases. That means the thicker the buffer layer, the faster the nucleation between grains occurred. The growth of the buffer layer at a low temperature produces an amorphous layer that accommodates the increase of strains due to the differences in lattice constants through the crystallization process during annealing the buffer layer at the growth temperature of the GaN film. Similar results are also observed by Chen et al., that growth of $\mathrm{GaN}$ buffer layer deposited at $300^{\circ} \mathrm{C}$, resulting in amorphous $\mathrm{GaN}$ that begins to crystallize at $500{ }^{\circ} \mathrm{C}$ [23]. When the buffer layer is grown at a low temperature, the supersaturation of the organic metal precursor TMGa is high enough to provide an increase in the chemical driving force for the formation of $\mathrm{GaN}$ and subsequently results in a high nucleation rate. In addition, from the results of SEM images, the surface morphology of $\mathrm{GaN}$ thin films grown with GaN or AlN buffer layers does not have crack patterns on the film surface, indicating that the buffer layer can reduce the strain that occurs between the substrate and the film.

We explored the influence of buffer layer thickness on the crystal structure of the GaN films deposited on top of it to understand better the role of the buffer layer on the crystal structure. Figure 2 shows the XRD diffraction pattern of the grown GaN films with the GaN buffer layer thickness variation. GaN films grown without a buffer layer (sample

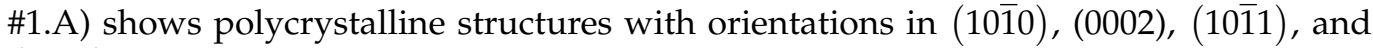
$(11 \overline{2} 0)$. The polycrystalline structure of the grown $\mathrm{GaN}$ on $\mathrm{Si}(111)$ is most likely due to 
threefold symmetry at the surface, which already gives a good rotational matching for the GaN, similarly observed by Dadgar et al., for the AlN buffer layer [12]. This matching is possibly present during buffer layer growth because the $(1 \times 1)$ surface reconstruction is the common reconstruction type in the presence of hydrogen [24]. The layer grows with an in-plane orientation of $\mathrm{AlN}$ are $\langle 0001\rangle\|\operatorname{Si}\langle 111\rangle,\langle 10 \overline{1} 0\rangle\| \operatorname{Si}\langle\overline{1} 12\rangle$, and $\langle\overline{11} 20\rangle \| \operatorname{Si}\langle\overline{1} 10\rangle]$ [12]. Therefore, without a buffer layer, $c$-axis orientated growth on (111) facets occur without the need for any treatment [25].

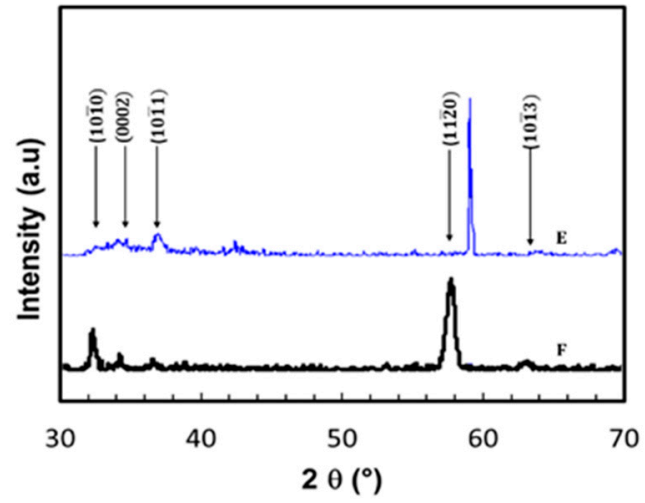

(a)

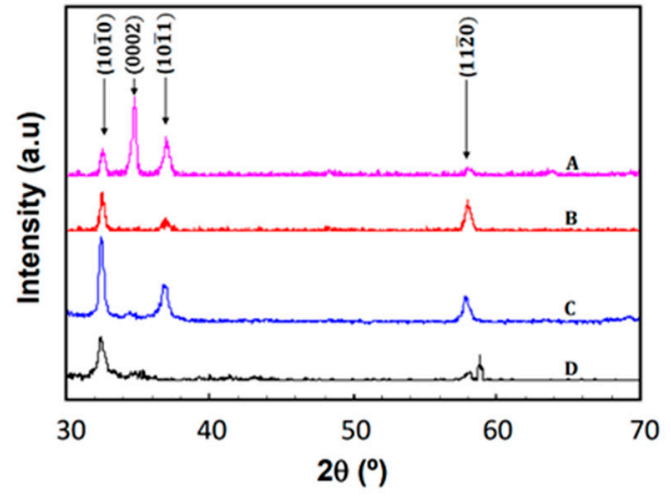

(b)

Figure 2. X-ray diffraction patterns of $\mathrm{GaN}$ grown at a temperature of $680{ }^{\circ} \mathrm{C}$ with a different thickness of buffer layers. (a) GaN buffer layer: A (without buffer layer), B (16 nm), C (33 nm), and D (50 nm); (b) AlN buffer layer: E (29 nm) and F (44 nm).

We found interesting characteristics of the GaN crystal structure when the buffer layer is introduced before the growth of GaN films. As shown in Figure 2, increasing the thickness of the buffer layer from $16 \mathrm{~nm}$ to $33 \mathrm{~nm}$ still produces GaN films with crystal orientation in the $(10 \overline{1} 0),(10 \overline{1} 1)$, and $(11 \overline{2} 0)$ while the crystal orientation of $(0002)$ is disappeared. At a buffer layer thickness of $50 \mathrm{~nm}$, the crystal orientation of $(10 \overline{1} 0)$ and $(11 \overline{2} 0)$ still exist, while other orientations diminished. In other words, the increase in the thickness of the buffer layer causes the grown GaN films to have a crystal orientation towards the (10 $\overline{1} 0)$ and $(11 \overline{2} 0)$. This growth mode is only possible if GaN templates are in the $(10 \overline{1} 0)$ and $(11 \overline{2} 0)$ planes. Since the template comes from crystallization of the amorphous GaN, this indicates that the crystallization GaN planes depend on the thickness of its amorphous layer. The dependence of GaN crystallites orientation on the thickness of the buffer layer was also observed by Ravash et al. [26]. The orientation of GaN crystallites is almost independent of the silicon surface direction when a thick AlN buffer layer is used. On the other hand, the crystallite orientation of GaN depends on the Si substrate orientation when a thin AlN seeding layer is applied.

Furthermore, the preferred orientation of the growth of $\mathrm{GaN}$ with $\mathrm{GaN}$ buffer layer in $(10 \overline{1} 0)$ and $(11 \overline{2} 0)$ plane orientation is believed to be attributed to the use of plasma nitrogen so that the growth temperature can be lowered significantly. The plasma nitrogen in our MOCVD system composes the excited states of neutral $\mathrm{N}_{2}{ }^{*}$ molecules in the second positive system with the $\mathrm{C}^{3} \Pi_{\mathrm{u}} \rightarrow \mathrm{B}^{3} \Pi_{\mathrm{g}}$ energy level transition [21]. Compared to the $\mathrm{N}_{2}{ }^{+}$ ions, the excited states of the $\mathrm{N}_{2}{ }^{*}$ molecule has lower energy, so that the growth of GaN using excited neutral molecular nitrogen $\left(\mathrm{N}_{2}{ }^{*}\right)$ is favorable to avoid damage to the layer

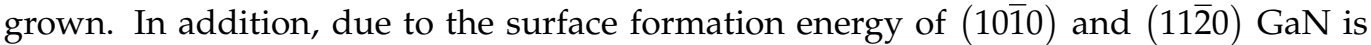
lower than that of (0001) [27], the growth in (1010) and (1120) is the preferred orientation compared to that of (0001).

The crystal orientation of GaN films grown with the AlN buffer layer thickness of $29 \mathrm{~nm}$ and $44 \mathrm{~nm}$ is similar to that of the GaN films grown without the buffer layer, except there is an additional (1013) crystal orientation (Figure 2b). GaN films using the AlN buffer layer have more crystal orientations than the GaN films grown with the GaN buffer layer, 
suggesting more grain boundaries associated with the number of crystal defects in the film. Therefore, the growth of GaN films with the GaN buffer layer is preferable because the resulting GaN films have preferred crystal structure oriented in the $a$-axis due to the lattice mismatch between $\mathrm{Si}$ and GaN in the $a$-axis is smaller than that of Si and AlN.

Strains and dislocations caused by the lattice mismatch and the thermal expansion coefficient differences between $\mathrm{GaN}$ and $\mathrm{Si}(111)$ substrates produce structural defects. The relationship between the lattice parameters ( $a$ and $c$ ) and the Miller indices (hkl) for the hexagonal structure is used to calculate the value of the lattice parameters [28].

$$
\sin ^{2} \theta=\frac{\lambda^{2}}{4 a^{2}}\left[\frac{4}{3}\left(h^{2}+k^{2}+l^{2}\right)+\frac{l^{2}}{\left(\frac{c}{a}\right)^{2}}\right]
$$

The strain was determined from the change of lattice constant calculated for diffraction angle of (1010) in $a$ direction, giving a magnitude of $a / a_{0}$, where $a_{0}$ is the lattice constant at the relaxation, which is $0.3189 \mathrm{~nm}$. Figure 3 shows the lattice-constant of GaN grown with different thicknesses of buffer layer obtained from the calculation of XRD measurements. The GaN films grown with the GaN buffer layer have a smaller $a$-lattice constant, while the GaN grown with the AlN buffer layer has a higher lattice constant than its relaxation value. This finding is also supported by the EDS measurement, that GaN films containing a nitrogen-vacancy show a lattice shrinking.

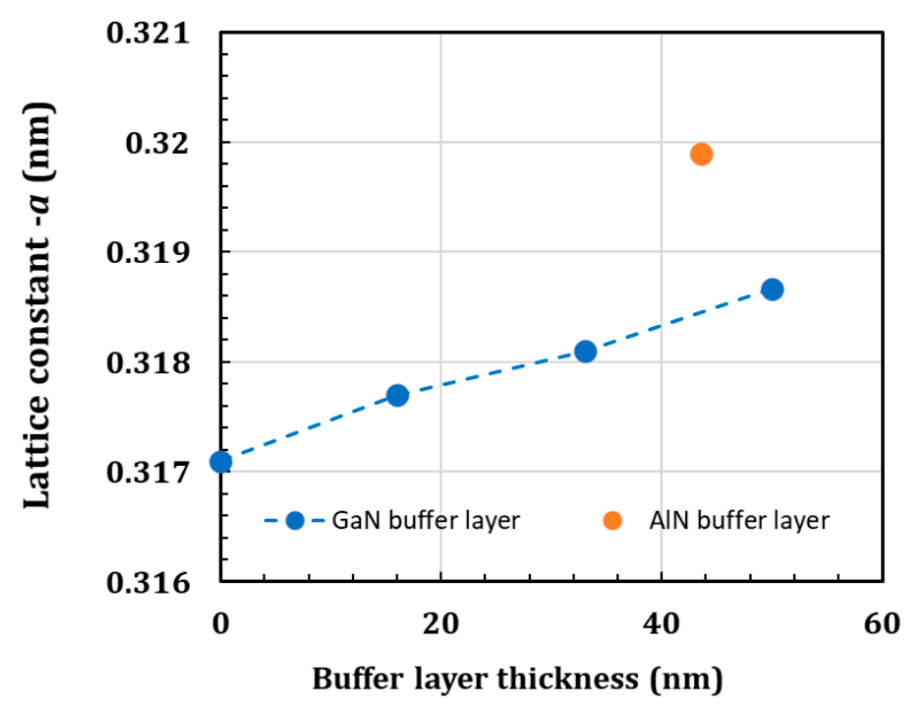

Figure 3. The calculated lattice constants in the $a$-axis of the GaN films grown on $\mathrm{Si}(111)$ substrates as a function of GaN buffer layer thickness.

The relation between the strain and the thickness of the buffer layer is shown in Figure 4. The GaN film deposited on $\mathrm{Si}(111)$ substrate with or without a GaN buffer layer showed the compressive strain, while GaN grown with the AlN buffer layer showed a tensile strain. Increasing the thickness of the GaN buffer layer can reduce the strain between the Si substrate and the GaN film until it reaches film relaxation. The strain reduction is associated with the surface diffusion barrier. When the film is in tensile conditions, the surface diffusion barrier increases, while when the film is in a compressive condition, the surface diffusion barrier strain decreases [29]. The dependence of strain on the thickness of the buffer layer in our standard PA-MOCVD growth employing Si(111) as a substrate follows a pattern similar to that using the sapphire substrate to grow c-axis oriented GaN films. The difference is in the thickness of the buffer layer, which results in a relaxed GaN layer with optimum films morphology and crystal structure. The thickness of the buffer layer is higher on a sapphire substrate than on a $\mathrm{Si}(111)$ substrate due to a more significant lattice mismatch between c-axis GaN on sapphire and $a$-axis GaN on Si. 


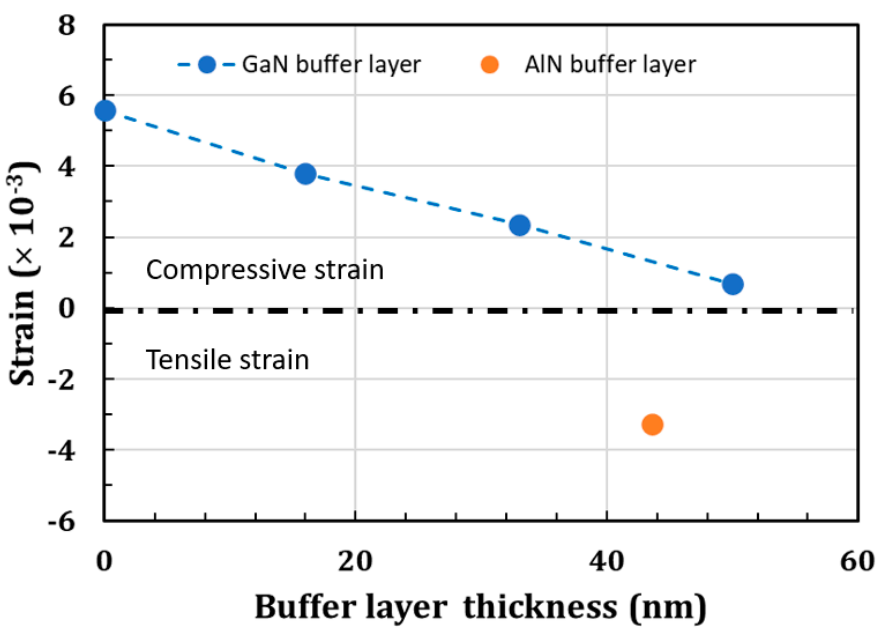

Figure 4. The calculated strain in the $a$-axis of the $\mathrm{GaN}$ films grown on $\mathrm{Si}(111)$ substrates as a function of buffer layer thickness. The GaN buffer layer causes compressive strain, while the AlN buffer layer causes tensile strain.

We used EDS measurement to analyze the $\mathrm{Ga} / \mathrm{N}$ atomic ratio of the grown $\mathrm{GaN}$ films. Table 1 shows the Ga/N atomic ratio of GaN films with GaN and AlN buffer layers. All samples have an atomic ratio of $\mathrm{Ga} / \mathrm{N}$ greater than 1, suggesting the $\mathrm{GaN}$ films are rich in Ga atoms or nitrogen deficiency. The nitrogen deficiency is commonly found in III-nitrides grown by MOCVD, and it is caused by nitrogen vacancies, which act as native defects in $\mathrm{GaN}$ [30]. Based on the crystal structure, morphology, strain relaxation, and $\mathrm{Ga} / \mathrm{N}$ atomic ratio, the optimum buffer layer thickness to produce high-quality GaN films is around $50 \mathrm{~nm}$.

\subsection{Growth of $A l G a N$}

Using the optimized $\mathrm{GaN}$ buffer layer grown at $500{ }^{\circ} \mathrm{C}$ for $15 \mathrm{~min}$ on $\mathrm{Si}(111)$ substrate, $\mathrm{AlGaN}$ films were deposited on top of the buffer layer with various $\mathrm{Al}$ vapor molar fractions. AFM images of the surface morphology of AlGaN thin films grown at a ratio of V/III $=650$ and a growth temperature of $700{ }^{\circ} \mathrm{C}$ are shown in Figure 5. Samples have variation in $\mathrm{Al}$ vapor molar fraction $\left(x_{v}-\mathrm{Al}\right)$ of $20 \%(5 \mathrm{a}), 30 \%(5 \mathrm{~b}), 40 \%(5 \mathrm{c})$, and $50 \%(5 \mathrm{~d})$. The $\mathrm{AlGaN}$ films surface morphologies are typically homogenous, with the RMS film's surface roughness of 2.13, 1.28, 0.74 , and $0.71 \mathrm{~nm}$ for Al-vapor molar fraction $\left(x_{v}-\mathrm{Al}\right)$ of $20 \%, 30 \%, 40 \%$, and $50 \%$, respectively. The smoother surface is achieved for a higher $x_{v}$-Al due to the smaller grain size. The grain size of AlGaN films is related to the radius of the atoms that compose the material, which affects the size of the crystal unit cell. Because the atomic radius of $\mathrm{Al}$ $(0.5 \AA)$ is smaller than that of $\mathrm{Ga}(0.62 \AA)$, increasing the $\mathrm{Al}$ composition on the film lowers the RMS value. Therefore, The RMS film's surface roughness of the AlGaN film decreases as the $x_{v}$ - $\mathrm{Al}$ increases from $20 \%$ to $50 \%$. The increase of $x_{v}$-Al causes the increase of $\mathrm{Al}$ solid composition in AlGaN. The same reasoning applies as the film thickness decreases as the $x_{v}$ - $\mathrm{Al}$ increases or the growth rate decreases as the $x_{v}$ - $\mathrm{Al}$ flow rate increases. In general, the AlGaN surface morphology is smooth and even. We hypothesized that the smoother surface morphology is associated with the growth process, which utilizes radical nitrogen in the form of the excited-neutral molecular state of nitrogen $\left(\mathrm{N}_{2}{ }^{*}\right)$ in the fourth positive system and the second positive system. The $\mathrm{N}_{2}{ }^{*}$ ion has lower energy than the $\mathrm{N}^{+}$and $\mathrm{N}_{2}{ }^{+}$ ions, which results in a flat film surface. 

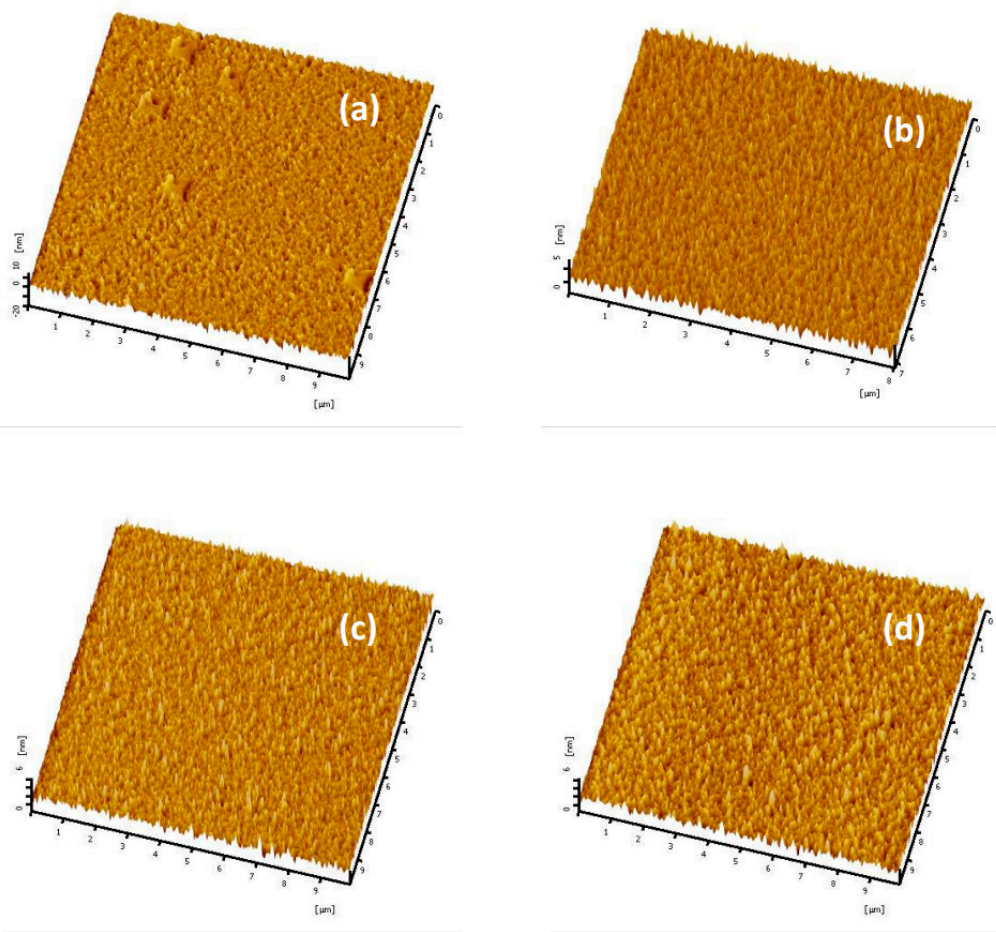

Figure 5. A two-dimensional AFM images of $\mathrm{AlGaN}$ films grown at $700{ }^{\circ} \mathrm{C}$ and a ratio of $\mathrm{V} / \mathrm{III}=650$ with different flow rates of TMAl/(TMAl + TMGa) $\left(x_{v}-\mathrm{Al}\right),(\mathbf{a}) 20 \%$, (b) 30\%, (c) $40 \%$, and (d) $50 \%$. The RMS surface roughness of AlGaN in (a-d) are 2.13, 1.28, 0.74 , and $0.71 \mathrm{~nm}$, respectively.

Figure 6 shows the XRD pattern of $\mathrm{AlGaN}$ grown with $x_{v}-\mathrm{Al}$ of $10 \%, 20 \%, 30 \%$, and $40 \%$ with a V/III ratio of 650 . AlGaN with $\mathrm{Al}$ fraction of $10 \%$ and $20 \%$ show polycrystalline structure in the orientation $(10 \overline{1} 0)$ and $(11 \overline{2} 0)$, with diffraction intensity on $(10 \overline{1} 0)$ much higher than $(11 \overline{2} 0)$. As the $x_{v}$-Al increases to $30 \%$ and $40 \%$, the $(11 \overline{2} 0)$ reflection plane vanishes, and the crystallographic structure is dominated by the (1010) plane, despite the reduced intensity. The XRD pattern shows shifting the $(10 \overline{1} 0)$ peak from $32.42^{\circ}(\mathrm{GaN})$ to $32.56^{\circ}, 32.66^{\circ}, 32.74^{\circ}$, and $32.82^{\circ}$ as $x_{v}-\mathrm{Al}$ set to $10 \%, 20 \%, 30 \%$, and $40 \%$, respectively. This angle shift is related to the $\mathrm{Al}$ solid fraction in the AlGaN film.

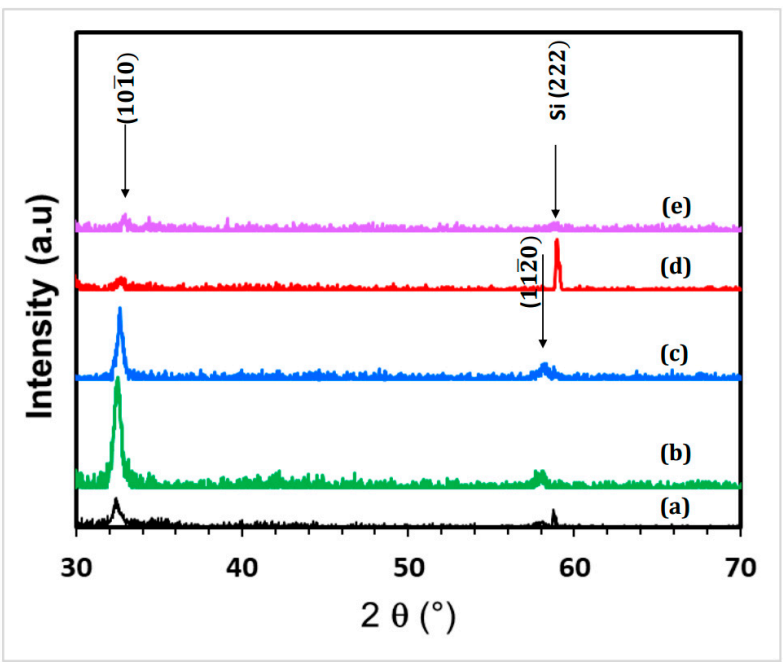

Figure 6. X-ray diffraction patterns of AlGaN films grown at a temperature of $700{ }^{\circ} \mathrm{C}$ and a V/III ratio of 650 with various flow rate of TMAl/(TMAl+TMGa) (a) $0 \%$, (b) 10\%, (c) 20\%, (d) 30\%, and (e) $40 \%$. 
The AlGaN film has a polycrystalline structure that grows along the $a$-axis because the lattice mismatch between $\mathrm{AlGaN}$ and $\mathrm{Si}(111)$ is smaller than that along the $c$-axis. Therefore, the crystallographic structure formed in the $a$-and $m$-plane has the highest chance than the $c$-plane. The growth of AlGaN in the $a$-axis direction indicates that the GaN buffer layer crystallizes in the $a$-axis direction. The crystallization of the amorphous GaN buffer layer plays an important role in producing a template for the growth of AlGaN. The crystallization process towards the $a$-axis, not towards the $c$-axis, is probably due to the interaction between the $\mathrm{Si}(111)$ planes and the formation of $\mathrm{GaN}$ energy on the $a$-axis. By applying such a buffer layer, we obtain highly oriented non-polar $\mathrm{AlGaN}$ on $\mathrm{Si}(111)$.

Since the diffusion coefficients of $\mathrm{Al}$ and $\mathrm{Ga}$ are almost the same, the flow rate of the molar fraction of group III precursor theoretically determines the fraction of $\mathrm{Al}$ and $\mathrm{Ga}$ in solid-phase AlGaN by using a simple relationship between solid-phase composition and vapor phase molar fraction, which is [31]:

$$
x_{A l}=\frac{F M_{A l}}{F M_{A l}+F M_{G a}}
$$

where $F M_{A l}$ and $F M_{G a}$ are the molar fraction of $\mathrm{Al}$ and $\mathrm{Ga}$ vapor, respectively. The molar fraction of $\mathrm{Al}$ in the solid phase of $\mathrm{AlGaN}$ can be deduced using Vegard's law from the shifting of the $(10 \overline{1} 0)$ peak. For $x_{v}$-Al up to $40 \%$, the stoichiometric transfer between the vapor and the solid phase occurs almost linear, as shown in Figure 7, indicating the strain has been relaxed and does not produce compositional fluctuations. No phase separation caused by inappropriate mixing of the two lattice components in the AlGaN alloy system is observed.

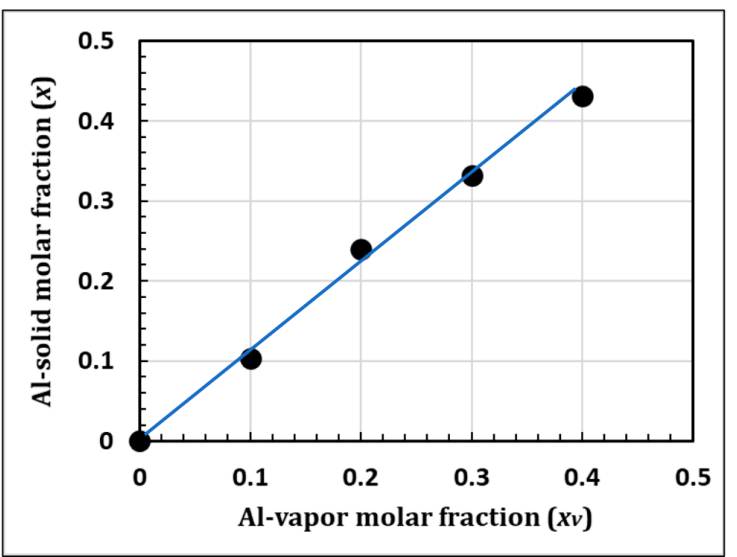

Figure 7. The dependence of the molar fraction of $\mathrm{Al}$ in the solid phase on the molar fraction of $\mathrm{Al}$ in the vapor phase $\left(x_{v}-\mathrm{Al}\right)$ of $\mathrm{AlGaN}$, grown at $700{ }^{\circ} \mathrm{C}$ with a $\mathrm{V} / \mathrm{III}$ ratio of 650 .

\section{Conclusions}

We investigated the effect of GaN and AlN grown at low temperatures as a buffer layer on the growth of non-polar GaN and AlGaN. The GaN film grown without the buffer layer was polycrystal, oriented in $a$-and $m$-plane and $c$-plane. The morphology was rough with a separated island was formed due to a low nucleation rate. However, the morphology and crystal orientation were greatly improved by introducing GaN or AlN buffer layer. The crystallized amorphous buffer layer effectively served as a growth template. It reduced the interfacial energy between the substrate and the GaN film, allowing for a faster coalition process between islands. We correlated the effect of the buffer layer on the growth of GaN with the use of low temperature and low energy of PA-MOCVD. The morphology and crystal orientation depended significantly on the thickness of the buffer layer. We found that the GaN buffer layer was superior to AlN, and the optimum thickness of the GaN buffer layer that gave excellent morphology and crystallinity was about $50 \mathrm{~nm}$. The GaN and AlGaN thin film grown on Si(111) substrate with GaN buffer layer showed a 
hexagonal crystallographic structure, with a preferred oriented in (10 $\overline{1} 0)$. The film's surface morphology was flat and homogenous, with less than $1 \mathrm{~nm}$ surface roughness.

Author Contributions: Conceptualization, P.A. and H.S.; investigation, H.S., S. and A.S.; writingoriginal draft preparation, H.S.; writing — review and editing, P.A.; supervision, P.A.; funding acquisition, P.A. All authors have read and agreed to the published version of the manuscript.

Funding: This research was partially funded by the Integrated Research Excellent Program, Ministry of Research and Technology, The Republic of Indonesia, under contract No. 01/Perj/Dep.III/ RUT/PPKI/II.

Institutional Review Board Statement: Not applicable.

Informed Consent Statement: Not applicable.

Data Availability Statement: Not applicable.

Acknowledgments: The authors acknowledge the Directorate General for Higher Education, The Ministry of Education and Culture, The Republic of Indonesia, and Research \& Community Services Council (LPPM), Institute of Technology Bandung for supporting this program.

Conflicts of Interest: The authors declare no conflict of interest.

\section{References}

1. Wong, M.S.; Nakamura, S.; Denbaars, S.P. Review-Progress in High Performance III-Nitride Micro-Light-Emitting Diodes. ECS J. Solid State Sci. 2020, 9, 015012. [CrossRef]

2. Wierer, J.J.; Tansu, N.; Fischer, A.J.; Tsao, J.Y. III-nitride quantum dots for ultra-efficient solid-state lighting. Laser Photonics Rev. 2016, 10, 612-622. [CrossRef]

3. Mishra, U.K.; Shen, L.; Kazior, T.E.; Wu, Y.-F. GaN-Based RF Power Devices and Amplifiers. Proc. IEEE 2008, 96, 287-305. [CrossRef]

4. Kukushkin, S.A.; Osipov, A.V.; Bessolov, V.N.; Medvedev, B.K.; Nevolin, V.K.; Tcarik, K.A. Substrates for epitaxy of gallium nitride: New materials and techniques. Rev. Adv. Mater. Sci. 2008, 17, 1-32.

5. Kahouli, A.; Kriouche, N. Estimation of the internal electric field inside (11-22) semipolar $\mathrm{GaN} / \mathrm{Al}_{0.5} \mathrm{Ga}_{0.5} \mathrm{~N}$ nanostructures and the radiative efficiency at low temperature. J. Appl. Phys. 2014, 115, 193106. [CrossRef]

6. Ngo, T.H.; Gil, B.; Damilano, B.; Valvin, P.; Courville, A.; de Mierry, P. Photo-induced droop in blue to red light emitting InGaN/GaN single quantum wells structures. J. Appl. Phys. 2017, 122, 063103. [CrossRef]

7. Wetzel, C.; Zhu, M.; Senawiratne, J.; Detchprohm, T.; Persans, P.D.; Liu, L.; Preble, E.A.; Hanser, D. Light-emitting diode development on polar and non-polar GaN substrates. J. Cryst. Growth 2008, 310, 3987-3991. [CrossRef]

8. Tanikawa, T.; Rudolph, D.; Hikosaka, T.; Honda, Y.; Yamaguchi, M.; Sawaki, N. Growth of non-polar (112̄0) GaN on a patterned (110)Si substrate by selective MOVPE. J. Cryst. Growth 2008, 310, 4999-5002. [CrossRef]

9. Chitnis, A.; Chen, C.; Adivarahan, V.; Shatalov, M.; Kuokstis, E.; Mandavilli, V.; Yang, J.; Khan, M.A. Visible light-emitting diodes using a-plane GaN-InGaN multiple quantum wells over r-plane sapphire. Appl. Phys. Lett. 2004, 84, 3663-3665. [CrossRef]

10. Craven, M.D.; Lim, S.H.; Wu, F.; Speck, J.S.; DenBaars, S.P. Structural characterization of nonpolar (1120) a-plane GaN thin films grown on (1102) r-plane sapphire. Appl. Phys. Lett. 2002, 81, 469-471. [CrossRef]

11. Schulze, F.; Dadgar, A.; Bläsing, J.; Hempel, T.; Diez, A.; Christen, J.; Krost, A. Growth of single-domain GaN layers on Si(001) by metalorganic vapor-phase epitaxy. J. Cryst. Growth 2006, 289, 485-488. [CrossRef]

12. Dadgar, A.; Schulze, F.; Wienecke, M.; Gadanecz, A.; Bläsing, J.; Veit, P.; Hempel, T.; Diea, A.; Christen, J.; Krost, A. Epitaxy of GaN on silicon-impact of symmetry and surface reconstruction. New J. Phys. 2007, 9, 389. [CrossRef]

13. Zhu, D.; Wallis, D.J.; Humphreys, C.J. Prospects of III-nitride optoelectronics grown on Si. Rep. Prog. Phys. 2013, 76, 106501. [CrossRef] [PubMed]

14. Wang, K.; Li, M.; Yang, Z.; Wu, J.; Yu, T. Stress control and dislocation reduction in the initial growth of GaN on Si (111) substrates by using a thin GaN transition layer. CrystEngComm 2019, 21, 4792-4797. [CrossRef]

15. Ma, J.; Zhu, X.; Wong, K.M.; Zou, X.; Lau, K.M. Improved GaN-based LED grown on silicon (111) substrates using stress/dislocation-engineered interlayers. J. Cryt. Growth 2013, 370, 265-268. [CrossRef]

16. Bolshakov, A.D.; Fedorov, V.V.; Shugurov, K.Y.; Mozharov, A.M.; Sapunov, G.A.; Shtrom, I.V.; Mukhin, M.S.; Uvarov, A.V.; Cirlin, G.E.; Mukhin, I.S. Effects of the surface preparation and buffer layer on the morphology, electronic and optical properties of the GaN nanowires on Si. Nanotechnology 2019, 30, 395602. [CrossRef]

17. Uen, W.-Y.; Li, Z.-Y.; Huang, Y.-C.; Chen, M.-C.; Yang, T.-N.; Lan, S.-M.; Wu, C.-H.; Hong, H.-F.; Chi, G.-C. Heteroepitaxial growth of GaAs on Si by MOVPE using a-GaAs/a-Si double-buffer layers. J. Cryst. Growth 2006, 295, 103-107. [CrossRef]

18. Remesh, N.; Chandrasekar, H.; Venugopalrao, A.; Raghavan, S.; Rangarajan, M.; Nath, D.N. Re-engineering transition layers in $\mathrm{AlGaN} / \mathrm{GaN}$ HEMT on Si for high voltage applications. J. Appl. Phys. 2021, 130, 075702. [CrossRef] 
19. Ni, Y.; He, Z.; Yang, F.; Zhou, D.; Yao, Y.; Zhou, G.; Shen, Z.; Zhong, J.; Zhen, Y.; Wu, Z.; et al. Effect of AlN/GaN superlattice buffer on the strain state in GaN-on-Si(111) system. Jpn. J. Appl. Phys. 2014, 54, 015505. [CrossRef]

20. Lin, Y.; Yang, M.; Wang, W.; Lin, Z.; Li, G. A low-temperature AlN interlayer to improve the quality of GaN epitaxial films grown on Si substrates. CrystEngComm 2016, 18, 8926-8932. [CrossRef]

21. Arifin, P.; Sutanto, H.; Subagio, A.; Sugianto, S.; Mustajab, M.A. Optimization of parameters for generating nitrogen plasma in plasma-assisted MOCVD growth of InGaN thin films. AIP Adv. 2019, 9, 115304. [CrossRef]

22. Weber, Z.L.; Sohn, H.; Newman, N.; Washburn, J. Electron microscopy characterization of GaN films grown by molecular-beam epitaxy on sapphire and SiC. J. Vac. Sci. Technol. B 1995, 13, 1578-1581. [CrossRef]

23. Chen, P.; Xie, S.Y.; Chen, Z.Z.; Zhou, Y.G.; Shen, B.; Zhang, R.; Zheng, Y.D.; Zhu, J.M.; Wang, M.; Wu, X.S.; et al. Deposition and crystallization of amorphous GaN buffer layers on Si(111) substrates. J. Cryst. Growth 2000, 213, 27-32. [CrossRef]

24. Naitoh, M.; Shimaya, H.; Watanabe, A.; Nishigaki, S. Hydrogen-induced restructuring and crater formation at Si(111) surfaces: A scanning tunneling microscopy study. Jpn. J. Appl. Phys. 1998, 37, 2033-2034. [CrossRef]

25. Sawaki, N.; Hikosaka, T.; Koide, N.; Tanaka, S.; Honda, Y.; Yamaguchi, M. Growth and properties of semi-polar GaN on a patterned silicon substrate. J. Cryst. Growth 2009, 311, 2867-2874. [CrossRef]

26. Ravash, R.; Blaesing, J.; Hempel, T.; Noltemeyer, M.; Dadgar, A.; Christen, J.; Krost, A. Impact of AlN seeding layer growth rate in MOVPE growth of semi-polar gallium nitride structures on high index silicon. Phys. Status Solidi B 2010, 248, 594-599. [CrossRef]

27. Dreyer, C.E.; Janotti, A.; van de Walle, C.G. Absolute surface energies of polar and nonpolar planes of GaN. Phys. Rev. B 2014, 89, 081305-1-081305-4. [CrossRef]

28. Suryanarayana, C.; Norton, M.G. X-Ray Diffraction: A Practical Approach; Plenum Press: New York, NY, USA, 1998 ; pp. $125-135$.

29. Lu, Y.; Liu, X.; Lu, D.-C.; Yuan, H.; Hu, G.; Wang, X.; Wang, Z.; Duan, X. The growth morphologies of GaN layer on Si(111) substrate. J. Cryst. Growth 2003, 247, 91-98. [CrossRef]

30. Ganchenkova, M.G.; Nieminen, R.M. Nitrogen vacancies as major point defects in gallium nitride. Phys. Rev. Lett. 2006, 96, 196402. [CrossRef] [PubMed]

31. DenBaars, S.P.; Keller, S. Metalorganic Chemical Vapor Deposition (MOCVD) of Group III Nitrides. In Semiconductor and Semimetal: Gallium Nitride (GaN); Pankove, J.I., Moustakas, T.D., Eds.; Academic Press: San Diego, CA, USA, 1998; Volume 50, pp. 11-35. 